\title{
ONDE ARTE, ANTROPOLOGIA E PolítiCA PODEM SE ENCONTRAR: PESSOALIZAÇÃo E METAFíSICAS DA INTERIORIDADE EM DISCURSOS SOBRE O SOFRIMENTO
}

\author{
Caio Gonçalves Dias ${ }^{1}$
Museu Nacional, UFRJ, Brasil
}

\begin{abstract}
Este ensaio explora a possiblidade de coletivização de vivências individuais de sofrimento - elaboradas pela produção antropológica e de artes visuais - a partir de processos de pessoalização. Por esse termo, compreendo a construção discursiva que produz uma identificação com os interlocutores, cuja eficácia reside no compartilhamento de um reconhecimento genérico como humanidade. Para isso, as produçôes de artistas e antropólogos operam metafísicas da interioridade; ou seja, utilizam-se mecanismos estilisticos capazes de acionar emocionalmente os interlocutores do texto ou obra. Subjaz a essa proposta a compreensão de que antropologia e arte podem produzir agenciamentos politicos de forma análoga, fazendo com que partilhem algumas mesmas questôes sócio-politicas.

Palavras-chave: antropologia da arte, política, sofrimento, coletivização
\end{abstract}

"Os Olhos de Gutete Emerita” é uma instalação do artista visual chileno Alfredo Jaar². O trabalho produz a pessoalização de uma situação de conflito, com foco para uma personagem específica: uma mãe que perdeu os filhos e o marido no genocídio de 1994, em Ruanda. Na obra, a usuária ou o usuário percorrem um longo corredor que exibe a história de Gutete, estampada em uma das paredes com letras brancas relativamente pequenas sobre um fundo negro. Em uma igreja, perto da capital Kigali, a mulher e sua família estavam refugiados com mais 400 membros da minoria tútsi quando foram emboscados e massacrados. Gutete conseguiu se esconder com uma de seus filhos, mas assistiu a seus dois meninos e marido serem executados a porretadas. Ao final desse corredor, uma grande mesa ocupa uma sala; sobre ela, há um milhão de slides

$1 \quad$ Contato do autor: caiogdias@gmail.com

2 O trabalho, cuja primeira versão data de 1996, pode ser visto no seguinte link: https://alfredojaar.net/projects/1996/the-rwanda-project/the-eyes-of-gutete-emerita-stack/ Acesso: 01/04/2021. 
dos olhos de Gutete, que podem ser manipulados pelos visitantes. A materialidade do texto contrasta-se à expressividade dos olhos que se encontram na sala contígua. Há um processo de pessoalização de uma situação classificável como "política" construído em dois âmbitos: primeiro, numa elaboração da guerra como experiência vivida, mas, também, na reprodução em série dos olhos de Gutete que, ao fazer com que a espectadora ou espectador se torne agente com o manipular dos slides, subjetiva o contato com a mulher a partir das pequenas imagens. Ocorre, pois, uma aproximação, corporalmente inscrita, entre usuária/o e a experiência representada. Ao mesmo tempo, a reprodução industrial dos olhos através dos slides - a quantidade é análoga ao número de vítimas ruandesas até 2000 - traz a sensação de que há uma exemplaridade: há outras mães como Gutete.

Esbarrar com fragmentos discursivos produzidos sobre situações de violência e sofrimento é algo comum cotidianamente. São produções discursivas que têm características e objetivos próprios e, em muitos casos, são produzidas a partir do testemunho das situações descritas. É possível que procurem estabelecer relações entre seus interlocutores e o sofrimento narrado para criação de empatia ou mobilização com um fim específico. Elas ganham eficácia, contudo, a partir do compartilhamento da valoração de certos significados, permitindo que sejam socialmente compreendidas. Para isso, transformam, discursivamente, uma situação individual em algo com que o interlocutor pode se identificar a partir de seus pertencimentos. Acredito que há uma eficácia simbólica desses discursos sobre o sofrimento colocada em sua habilidade para transformar as situações vividas individualmente em algo que, mesmo que indiretamente, diz respeito ao coletivo a partir do que nos define como humanidade.

Esse processo pode ser compreendido como pessoalização ${ }^{3}$, ou seja, o versamento, numa enunciação, de uma questão como se fosse coletiva a partir da inclusão do locutor, do interlocutor e, também, da pessoa sobre a qual se narra enquanto pessoas do discurso, em sentido afeito ao sintático-gramatical. Minha proposição interpretativa inspira-se livremente na possibilidade de gramaticalização do termo "a gente" ${ }^{4}$, levando em conta sua passagem de um substantivo ("gente") para uma locução pronominal indefinida ("a gente") e, posteriormente, para uma locução pronominal pessoal ("a gente”, mais uma vez). A partir da leitura de Benveniste , gostaria de pensar a pessoalização como uma espécie de eixo que comporta diversos graus na direção da "pessoa" - que compreendo, talvez num esgarçamento do pensamento de Benveniste, como indício de uma tentativa de humanização coletivizada genérica ${ }^{6}$.

3 Utilizo essa noção em detrimento das ideias de "modos subjetivação" ou de "individualização", porque, por um lado, estas me parecem ligadas à possibilidade de sujeição/construção de si e, por outro, de diferenciação em relação a um escopo social ampliado. Na minha perspectiva, a ideia de pessoalização é, contudo, capaz de dar conta de um processo coletivizante, mas não necessariamente individualizado; está relacionada a uma humanidade genérica, que não é obrigatoriamente análoga à subjetividade ou à individualidade. De todo modo, já que essas três noções gravitam em torno de um mesmo campo semântico, não gostaria de perder de vista as críticas do sujeito como enunciador necessário de uma metafísica ocidental (Derrida, 2006), as possibilidades inscritas em modos de subjetivação como cuidados de si (Foucault, 2004), os diferentes tipos de individualismos e suas implicações para modernidade (Simmel, 2005; Velho, 2003), assim como uma crítica a processos capitalísticos contemporâneos que impactam a subjetividade (Guattari, Rolnik, 2005).

4 Sobre esse ponto, ver Borges, 2004. A leitura de Benveniste feita por esse autor também complementou a construção argumentativa deste artigo.

5 Ver Benveniste, 1966 (especialmente os capítulos "La nature des pronoms" e "De la subjectivité dans le langage"). Outras discussões em torno do pronome francês "on" podem ser encontradas em Blanche-Benveniste (2003) e Landragin \& Tanguy (2014).

6 Mesmo que baseadas no francês, as elaborações de Benveniste apontam para questões gerais que estariam ligadas ao uso da língua num sentido estrutural. Nessa perspectiva, a questão da pessoalização de pronomes que não 
Há, em toda enunciação, uma autoridade do enunciador (“eu”, pessoa), que funda - a partir de sua agência - o interlocutor ("tu”, pessoa), e que fala sobre "ele" (não-pessoa). "Eu" e "tu", participantes do diálogo, situam-se na linguagem como "pessoa", ao passo que "ele" - sobre quem se fala - é, em tese, privado dela. No processo de pessoalização, o sujeito sobre o qual se fala também é instaurado enquanto pessoa. É nesse sentido que seria possível pensar sobre uma passagem de um polo da "não-pessoa" para o de "pessoa", produzindo a pessoalização do "ele" a partir de uma afirmação de um potencial de correlação substantiva entre indivíduos. Nesse caso, isso só seria possível quando se afirma a humanidade do "ele", no movimento que é correlato àquele que faz com que seja possível um uso genérico do "a gente", que inclui o "eu", o "tu" e o "ele". Pressupõe-se, portando, que o indivíduo sobre o qual se fala também poderia ser o locutor. Produz-se um potencial de intercambialidade: se o sujeito sobre o qual se fala fosse o agente locutor, não seria produzida uma grande mudança no enunciado.

Num nível pragmático da linguagem, porém, a pessoalização é sempre algo potencial, que não se pode efetivar de modo completo - "ele" não pode ser "eu", por mais que se criem elementos de identificação. Um "falar por alguém” não é completamente possível; a instância que se sobrepõe - já que é a mesma que instaura a pessoalidade de "a gente" - é a do "eu”. O "a gente", enquanto pessoa, funda-se no "eu”. Dessa maneira, a pessoalização é, necessariamente, um recurso discursivo do "eu": veja que mesmo o "tu" é instaurado pelo "eu". Toda enunciação tem, portanto, feições autocentradas.

Ao mesmo tempo, essa operação está inserida em processos mais amplos de significação e, talvez, reconhecer esse ponto seja um esforço de abandonar parte do caráter propriamente estruturalista da argumentação apresentada até aqui. Ela é estetizada e utiliza procedimentos reconhecidos no mundo (Becker, 1982: 35) em que se encontra - e aquela que envolve situações de sofrimento não é diferente. É válido notar, ainda, que os diversos agentes dessas construções têm procedimentos que se ligam à comunidade interpretativa (Becker, 2009) com que dialogam.

Acredito, e é em torno deste ponto que a argumentação deste ensaio se desenvolve, que essas operações - por um lado, o processo de pessoalização, e, por outro, sua instauração a partir de preceitos de significação reconhecidos por certa comunidade interpretativa - são utilizadas, entre outros, tanto por trabalhos antropológicos como pelas obras de arte. Os textos acadêmicos que lidam com situações de sofrimento, nesse contexto, também o fazem a partir de escolhas estéticas que possuem implicações e traduções analíticas. Ao mesmo tempo, as representações colocadas no trabalho de arte acabam por informar sobre certa situação e tornam-se igualmente analíticas.

Para produzir essa aproximação, esse encontro, gostaria de trazer à baila a perspectiva de Alfred Gell para antropologia da arte. Como o autor explica-nos, essa modalidade de antropologia "focuses on tie social context of art production, circulation, and reception, rather than the evaluation of particular works of art, which, to my mind, is the function of a critic" (1998, p. 3). Seria o caso, assim, de nos interrogarmos sobre a maneira como as obras de arte são, também elas, agentes em certas relações sociais, construindo uma "anthropological theory in which persons or 'social agents' are, in certain contexts, substituted for by art objects" (Op. Cit., p. 5). Gostaria de propor, experimentalmente, que pensássemos a própria antropologia como um

necessariamente têm essa função sintática originalmente é um fenômeno observado também em português (ver o já citado trabalho de Borges, 2004) e em inglês (nesse caso a partir do termo “one”; ver Mignot, 2015). 
agente social, assim como faríamos com a arte - ou os objetos de arte - na perspectiva de Gell. Objetos antropológicos - os textos, filmes, imagens, entrevistas, exposições que produzimos também possuem agência. Além disso, tanto arte como antropologia podem desempenhar papéis semelhantes nos processos de pessoalização, produzindo posicionamentos no jogo político a partir de mecanismos análogos.

É necessário, para isso, estabelecer uma compreensão mais direta do que significa, na perspectiva deste ensaio, o trabalho a partir do domínio político. Compreendo a politização como a descrição ou análise de processos que, em nossa modernidade, vêm sendo marcados pelo "desenvolvimento de técnicas de poder orientadas para os indivíduos e destinadas a dirigi-los de forma contínua e permanente" (Foucault, 1990: 79). Nesse sentido, tanto a produção intelectual quanto a artística estariam conectadas a esse cenário ampliado, sendo algumas de suas condições de possibilidade orientadas por ele. Ao mesmo tempo, e mesmo por isso, as produções desse tipo também afirmam-se como possibilidade de crítica (op. cit.: 98), de criação de uma imaginação de cenários e vidas diferentes daqueles que se produzem contemporaneamente. A perspectiva política, como a considero, é, assim, aquela que é capaz de confrontar a maneira como habitualmente pensamo-nos a nós mesmos. "Existem momentos na vida onde a questão de saber se se pode pensar diferentemente do que se pensa, e perceber diferentemente do que se vê, é indispensável para continuar a olhar ou a refletir". Trata-se, assim, de "tentar saber de que maneira e até onde é possível pensar diferentemente em vez de se legitimar o que já se sabe" (Foucault, 1999: 15) ${ }^{7}$.

Este texto articula-se a partir dessa reflexão a partir de dois materiais. Por um lado, a já citada obra de Alfredo Jaar; por outro, para dar corpo à aproximação, analisarei o livro What really matters de Arthur Kleinman. São dois trabalhos identificáveis, pois, com o domínio político - especialmente no caso de Jaar, que trata sua arte como política. Gostaria de considerar que a identificação de certa obra ou texto como sendo políticos pode produzir uma espécie de posicionamento fático, em que a adjetivação nem sempre encontra amparo mais direto nas produções. Minha postura, no entanto, é colocar essa questão em suspenso e perscrutar as estratégias que podem subsidiar uma perspectiva crítica, tal como assinalado acima.

II

A obra de Alfredo Jaar faz com que uma história individual seja conhecida por muitos interlocutores, produzindo identificação com a situação vivida por uma mãe que deveria ser publicizada para que outros, cientes de seus horrores, pudessem se sensibilizar. A eficácia dessa narrativa em especial está situada numa triangulação: num vértice, há Gutete, sua história e cotidiano; no outro, há o artista, que opera sobre essa narrativa a partir de certas concepções e mecanismos de significação próprios; e, por fim, há a usuária ou o usuário da obra, a quem se possibilita o contato com Gutete e sua história.

7 Não por acaso, para além das questões citadas, a pesquisa de Foucault entre 1976 e 1984 - os anos que separam o primeiro volume da História da Sexualidade dos outros dois que publicou em vida - redunda num interesse significativo pelo tema do cuidado de si e da estética da existência como contraface crítica dos processos modernos de governo (Foucault, 1985). 
Em seu Distant Suffering, Luc Boltanki identifica uma confluência entre as dimensões políticas da "piedade", que pontuam a relação com o sofrimento alheio contemporaneamente especialmente na "questão humanitária" -, e as próprias condições de possibilidade dessas atuações colocadas nas vivências individuais. As diversas ações humanitárias - que, ao que parece, poderiam ser compreendidas, ao mesmo tempo, como realização política e indício sociológico -, estariam calcadas numa identificação suficientemente geral - por isso, à distância -, mas sem se desligar do sofrimento efetivo. Produz-se uma identificação por parte do espectador ou espectadora com relação ao sofrimento do outro, mesmo que não seja diretamente afetado/a pela situação.

No caso da obra de Jaar, o episódio de sofrimento é presenciado, mas o processo de politização reside exatamente numa elaboração discursiva destacada do evento e agenciada por um sujeito desinteressado. A capacidade de apiedar-se com a dor alheia, situada à distância, é baseada numa aptidão mais ou menos genérica de se colocar no lugar do outro.

É como se essa generalidade pudesse garantir uma capacidade, também ela geral, de condoer-se com o sofrimento dos semelhantes, numa humanidade definível em termos gerais. É aqui que o individualismo moderno contemporâneo ocidental se torna basilar para a eficácia dessas proposições. A compreensão do mundo social a partir dele é fundamento para as práticas políticas; os próprios movimentos de identificação com o sofredor dão-se, justamente, pela possibilidade - calcada na experiência individualista do mundo - de conceber-se no lugar do outro, efetivada por uma abstração do sujeito como algo (auto-)manipulável.

A metafísica da interioridade, uma noção também de Boltanski, pode ser lida em paralelo ao procedimento de Alfredo Jaar com Gutete. $\mathrm{O}$ modo como o artista descreve a experiência no texto e a construção da obra de modo geral enfatizam um processo comunicacional amplamente marcado por uma assimilação emocional. A comunicação entre Gutete e Alfredo dá-se pelo olhar; a fala é secundária. Nas palavras de Alfredo que aparecem na instalação, importa o que é expressado pelo olhar: "I remember her eyes. The eyes of Gutete Emerita". A conexão emocional entre os dois e, especialmente, sua expressão discursiva através da obra, é característica dessa metafísica. Ao mesmo tempo, é também esse dispositivo que garante a identificação do/a usuário/a da obra com a "realidade" representada. Isso é produzido pela inscrição corporal dessas relações, pois seu aspecto emocional - que é um agenciamento do corpo e, em tese, difícil de ser fingido - é garantidor de sua veracidade.

$\mathrm{Na}$ apresentação dos "Olhos de Gutete", em vez de uma legenda simples, um texto serve de ambientação para o que será visto na sala em que se encontram os "olhos”. Em Diante da Dor dos Outros, Susan Sontag (2003) analisa, entre outros pontos, o papel das legendas nas fotografias que envolvem o sofrimento. Um caso exemplar é a discussão sobre a obra de Sebastião Salgado que, ao apresentar belas fotografias sem legendas, estaria apenas estetizando o infortúnio alheio?.

8 "In a topic of sentiment the relationship of spectator and unfortunate is real, authentic and thereby touching, not when it is established superficially with regard to appearances, but when it is heart to heart, going from interiority to interiority" (Boltanski, 2004: 81).

9 "Na fotografia de atrocidades, as pessoas querem o peso do testemunho sem a nódoa do talento artístico, tido como equivalente à insinceridade ou à mera trapaça” (Sontag, 2003: 26). 
O texto na obra de Jaar, contudo, informa e emociona. É informativo ao explicar o contexto em que foram fotografados aqueles olhos e, com essas informações, a/o usuária/o torna-se capaz de condoer-se pela situação de Gutete. A leitura desses fatores em conjunto é o que garante a eficácia do trabalho. Se levarmos a sério as proposições de Boltanski, a politização da piedade e a capacidade de simpatizar com o sofrimento do outro são processos que se concretizam simultaneamente. $\mathrm{O}$ alcance de apenas uma dessas propriedades - ou uma politização pura a partir da informação ou, ainda, uma emocionalidade esvaziada - possivelmente não emprestaria um sentido político à obra.

Um outro argumento de Sontag (2003) também complexifica a análise: a afirmação de que jornalistas cumprem a função de ser espectadores de calamidades ocorridas em outros países, propagando-as para outros contextos, e que essa situação seria uma experiência moderna essencial. Também decisivo, como a autora pondera ao longo do ensaio, é o que deixam de mostrar; os "recortes da realidade" que produzem sempre excluem agentes e versões. Em consequência, é a própria natureza artística do trabalho tido como apenas jornalístico que pode ser percebida.

O trabalho do fotojornalista tem, pois, uma dimensão marcadamente artística, que pode ser vista de modo análogo no caso da obra de Jaar. Trata-se de um trabalho de artes visuais que usa a fotografia, mas num suporte que não é o clássico em exposições fotográficas - o contato que se tem com os olhos de Gutete é feito através de slides. A questão é que, mesmo com essa subversão do formato clássico de exposição fotográfica, o slide que se manipula também é lido como um indício de "realidade", como reprodução do acontecido.

A politização da obra, deste modo, residiria exatamente em sua capacidade de lidar com o real de maneira direta e aparentemente objetiva. Se, de alguma forma, Sontag mostra como se deve considerar a estetização de retratações do real, no caso de Jaar o contexto em que se insere lida com o inverso: a possibilidade de politização do eminentemente estético. $\mathrm{O}$ fato de utilizar-se do acontecido (e testemunhado) e do político não é algo que deva ser compreendido de modo trivial nas artes visuais do século XX. Essa é uma escolha estética e política que se contrapõe a outras possibilidades de atuação que foram alvo de disputas ao longo do tempo.

Por fim, é importante mencionar que Sontag cita o genocídio dos tútsis ruandeses - dos quais Gutete faz parte - para ilustrar uma característica das fotos de atrocidades contemporâneas: imagens frontais completas dos mortos são mais comuns em lugares remotos ou exóticos. Esse contraste de realidades e contextos opera também uma diferenciação hierarquizada de sofrimentos possíveis. Dito de outro modo, o contato com a experiência de sofrimento de Gutete acaba por qualificar o repertório de "sofrimentos" do/a usuário/a médio/a da obra: quais seriam suas chances de passar por um massacre étnico? Essa diferença na escala de sofrimentos também coopera com uma solidarização, produzida pela isenção de quem tem contato à distância com a situação de sofrimento (Sontag, 2003: 86).

O trabalho de Jaar pode, assim, ser lido como produtor de um processo de pessoalização, já que transforma em questão coletiva uma situação individualmente experienciada. A teoria da enunciação é produtiva para essa análise, na medida em que é o trabalho do artista que instaura tanto a vítima, Gutete, como o usuário ou usuária da obra, já que mesmo sua possibilidade de interação, a partir da manipulação dos slides, é aquela construída por Jaar. Nota-se, portanto, que sua politização se situa na afirmação dêitica como pessoa tanto do interlocutor quanto do indivíduo que vive a situação descrita. Trata-se, assim, de uma construção discursiva sobre o 
sofrimento alheio que faz uso de mecanismos estilísticos e formais reconhecidos como legítimos em certos mundos. E, nesse caso, é importante identificar com quem essas obras querem dialogar, como operam seus mecanismos de comunicação e que parâmetros utilizam para isso.

III

Para produzir contraste e ajudar a complexificar a argumentação, será importante fazer o caminho inverso. Procuro, agora, identificar outra produção que também apresenta escolhas estilísticas, podendo ser identificadas como estéticas, voltadas para processos de informação, mas que produzem, ao mesmo tempo, uma aproximação interiorizada entre leitores e situações narradas: textos de caráter antropológico que têm, deste modo, outros acadêmicos como interlocutores privilegiados (mesmo que não únicos) e que também estão centrados em situações de sofrimento. Buscando compreender que mecanismos estéticos ajudam a construir posturas analíticas, analisarei um livro de Arthur Kleineman, que considera a dimensão "autobiográfica" de seu trabalho. Pretendo mostrar como, nesse cenário, mecanismos estilísticos também estão relacionados à metafísica da interioridade para produzir pessoalização, como trabalhado na seção anterior deste ensaio.

O estatuto da etnografia e o trabalho do tempo têm papel fundamental para Arthur Kleinman. No livro What Really Matters, o autor expõe um relato bastante peculiar de seu percurso como antropólogo e psiquiatra, focando em personagens com os quais se relacionou durante sua trajetória. De texto singular, cada capítulo é centrado em um desses indivíduos (ou dois, em um deles), descritos com uma adjetivação rara em textos acadêmicos, mas que ajudam a dar espessura à narração. Alguns personagens foram pacientes de Kleinman; outros foram apenas entrevistados ou, ainda, pessoas com as quais estabeleceu contato tanto num sentido pessoal - o capítulo 7, focado em dois "mentores" do autor, é melhor exemplo nesse sentido - ou através de pesquisa - como o capítulo 8 , de natureza histórica e dedicado ao antropólogo W. H. R. Rivers.

A proposta do livro é produzir relatos e reflexões sobre a maneira como as pessoas lidam com situações-limite, perigosas e/ou de incertezas, buscando viver uma vida moral. Este último termo refere-se "to our sense of right and wrong. When we say we want to live a moral life, we mean one that embodies our own moral commitments" (Kleinman, 2006: 2). Esses comprometimentos morais revelam-se, contudo, em composição com um cenário ampliado, em nível comunitário e/ou social. Há, assim, uma articulação entre os anseios individuais - com crenças morais singulares - e as comunidades morais que cercam esses mesmos indivíduos. As situações-limite tendem a colocar essas esferas em tensão, já que os comprometimentos morais são postos à prova em situações sobre as quais não se tem domínio efetivo.

Nesse cenário, cabe refletirmos sobre a maneira como o tempo diz respeito às compreensões, categorias e subjetividade também do pesquisador. Há o tempo do paciente ou interlocutor, suas tensões e questões que surgem e, em tese, são trabalhadas quando numa situação clínica. Chama atenção, no entanto, a maneira como o tempo do pesquisador tem enorme implicação nas leituras que faz das vivências dos sujeitos com os quais interage. Assim, algumas questões apresentadas por seus pacientes só tornam-se claras para o próprio psiquiatra tempos depois, tendo, inclusive, seus diagnósticos repensados. Ocorre um processo que instaura um 
tempo etnográfico específico e lida com uma duração mais ampla do que os meses habituais de trabalho de campo.

Esse ponto produz um desdobramento específico: exige uma transmutação textual que possa dar espessura a essa temporalidade extensa. Um dos recursos utilizados para isso é o que venho chamando de pessoalização. Kleinman utiliza-se recorrentemente da possibilidade de que as questões de seus interlocutores sejam coletivas para construir uma empatia com o leitor. Para isso, usa numerosas vezes a primeira pessoa do plural em suas construções, articulando as experiências, sensações ou avaliações narradas com as suas próprias:

None of us, certainly not I, can be a neutral observer of how our friends, family members, and we ourselves come to the end. Neither of my professional backgrounds as anthropologist or psychiatrist prepares me with the technical terms and professional theories to deal with this core human condition. The messy mix of emotion, relations, and values that we all inevitably find ourselves in is the human condition (Grifo no original; Kleinman, 2006: 161).

Essa argumentação certamente ganha eloquência quando Kleinman escreve seu capítulo autobiográfico. Mais do que o texto em si, é importante examinar a maneira como ele é justificado:

This is as true for me as for those whose stories I have narrated. Hence this chapter turns to autobiography in order to describe my own condition — subjectivity, local world, moral experience — and to suggest how it may influence the interpretations I am offering. I will begin by narrating an interlocking set of images, emotionally loaded memories that seem to me to authentically express who I am and what has been at stake for me (2006: 163).

Nota-se, assim, o acabamento de uma proposição geral do livro: examinar possibilidades individuais de lidar com situações limítrofes tomadas como reverberações de uma condição geral, humana. Esse ponto inscreve, de maneira refinada, um regime de generalização próprio que produz um compartilhamento de experiência entre o autor e seus interlocutores, mas que tem também, no horizonte de uma condição humana, o leitor como alvo.

É nesse sentido que o trabalho antropológico - mesmo que não exatamente etnográfico - trabalha de modo direto para pessoalização: do autor, dos interlocutores, dos leitores. Essa questão deixa transparecer características que se ligam a uma compreensão mais ampla do mundo social. Pode-se pensar num universo moral compartilhável que, se é identificado através de percepções e narrativas de sujeitos localizados, está situado para além do indivíduo. Essa teoria, porém, é suficientemente maleável, porque, no processo de escrita - e também na fala efetiva dos sujeitos com os quais se interage -, esses mesmos padrões são constantemente ressignificados através das vivências pessoais. Assim, é perceptível nas construções narrativas uma tensão constitutiva, uma vez que não se trata de algo que possa ser resolvido, entre a vivência individual e o coletivamente suposto.

Nesse processo, porém, operam-se mecanismos estilísticos que produzem uma aproximação com o leitor; poderíamos, mais uma vez, evocar a noção de metafísica da interioridade. No texto de Kleinman, pululam metáforas e comparações que trabalham nesse sentido. Além delas, há uma passagem das narrações, ouvidas pelo autor, para as narrativas, estas selecionadas e escritas por Kleinman. Há estratégias textuais que, ao mesmo tempo que obliteram essa passagem, acabam por produzir eloquência a partir do testemunho. É assim que, habitualmente, procura descrever "a personagem" do capítulo com os atributos físicos - e, eventualmente, a narração dos 
próprios pacientes, transcritas, entremeiam o texto com o mesmo objetivo. Essas narrações, por fim, são as agentes de memória para o próprio psiquiatra, "assombrado" por essas histórias ${ }^{10}$, que possuem agências. Gostaria de enfatizar, portanto, uma triangulação relativa entre a experiência narrada pelos interlocutores, a audição pelo psiquiatra/antropólogo e o texto efetivamente produzido. É este último que se afirma como elocução, capaz de instaurar, como pessoas, o autor, as pessoas sobre as quais se fala e também o leitor.

IV

A escolha por trabalhos construídos a partir do testemunho é interessada, já que permite o emprego da pessoalização como metáfora explicativa de modo eloquente. Nesses casos, as peças discursivas produzem seus interlocutores não apenas no sentido de representá-los, mas, também - já que não existem decalques do real -, numa perspectiva inventiva (Wagner, 2015), ficcional (Geertz, 2008). Esse ponto não invalida esse tipo de trabalho. Ao contrário, uma elaboração construída a partir de vivências individuais e trajetórias pode ser pertinente de uma perspectiva analítica e também para apresentar certa postura política crítica, se compreendemos o termo como possibilidade de produzir imaginações de vidas alternativas àquelas que temos.

Para isso, porém, parece-me que a questão central para que esse jogo inventivo que cerca a produção discursiva em torno do testemunho do sofrimento tenha respaldo ético-político e vá além de um exercício estético é a afirmação de uma intenção política do texto/obra e uma situação direta do emissor. Começando por este último ponto, o texto antropológico considerado neste ensaio é mais bem-sucedido; o caráter autobiográfico do trabalho efetiva essa preocupação de uma maneira mais radical e, ao mesmo tempo, adensa o texto na medida em que o processo de pessoalização se efetiva para o emissor de maneira qualificada e direta.

Por outro lado, a pertinência política da descrição tem sua espessura determinada pela necessidade de produzir empatia com os/as leitores/as ou usuários/as da obra. Para isso, é necessário que haja uma confluência entre os processos de descrição e o que se pretende produzir com ele. Não se trata, aqui - ou não se trata mais, se quisermos situar essa discussão na história da antropologia disciplinar ou do exercício fotográfico clássico -, de produzir uma espécie de retrato de formas culturais sem agência. É necessário, agora, um posicionamento claro com relação aos objetivos de publicizar certas vidas, num sentido crítico que rechace sistematicamente uma alteridade exotizante. E, aqui, os discursos sobre o que se convenciona classificar como sofrimento ganham eloquência, pois afirmam-se como oportunidades para examinar cenários-limite - individuais e coletivos.

E, se o objetivo dos textos fundados no testemunho é produzir empatia, o uso de mecanismos afeitos a uma metafísica da interioridade parece incontornável. Recursos estéticos permeiam os usos de narrativas que têm por objetivo torná-las próximas tanto dos sujeitos "representados" como daqueles que entram em contato com os fragmentos discursivos produzidos. Mas, se a eficácia genérica dos discursos sobre o sofrimento à distância reside, exatamente, numa capacidade geral "humana" de condoer-se com o sofrimento alheio, esse processo de aproximação dos

10 "Narratives can haunt. What haunts our memories is more than images and words, but the actual world of experience that stands behind them" (Kleinman, 2006: 217). 
sujeitos narradores, calcado em recursos estilísticos, também acaba por fazer com que o texto acadêmico fique mais próximo dos sujeitos leitores. $\mathrm{O}$ espaço para "identificação" a partir do emocional, mesmo nos textos acadêmicos, é, portanto, uma ferramenta importante e cujo uso deve ser considerado a partir de uma perspectiva crítica.

Uma leitura final, que certamente a extensão deste ensaio não seria capaz de esgotar, é que as confluências das produções analisadas - tanto o livro como a obra de arte - sejam devedoras, exatamente, das condições sociais de produção do sofrimento como tal. Essa produção é, aqui, entendida como os agenciamentos mobilizados para constituí-la enquanto algo que seja passível de intervenção, compreensão e identificação por outros sujeitos formados numa mesma tradição sociocultural. Assim, tal produção teria uma importância política significativa, afirmando-se como um recurso para crítica e mobilizações sociais. É nesse registro que se pode pensar que arte e antropologia se encontram em possibilidades análogas de produzir agenciamentos políticos - e, neste âmbito, compartilham potencialidades e questões sociais e éticas.

\section{BIBLIOGRAFIA}

Becker, Howard S. 1982. Art Worlds. Los Angeles: University of Califórnia Press. 2009. Falando da Sociedade: Ensaios sobre as diferentes maneiras de representar o social. Rio de Janeiro: Zahar.

Benveniste, Emile. 1966. Problèmes de linguistique générale. Paris: Gallimard.

Blanche-Benveniste, Claire. 2003. "Le double jeu du pronom on". In. La syntaxe raisonnée: Mélanges de linguistique générale et française offerts à Annie Boone à l'occasion de son 60e anniversaire. Louvain-la-Neuve, Belgique: De Boeck Supérieur, pp. 41-56.

Boltanski, Luc. 2004. Distant Suffering: Morality, Media and Politics. Cambridge: Cambridge University Press.

Borges, Paulo. 2004. A gramaticalização de a gente no português brasileiro: análise histórico-social-linguística da fala das comunidades gaúchas de Jaguarão e Pelotas. Tese de Doutorado em Letras, Universidade Federal do Rio Grande do Sul (UFRGS). Porto Alegre.

Derrida, Jacques. 2006. Gramatologia. trad. br. Mirian Chnaiderman e Renato Ribeiro. São Paulo: Perspectiva.

Foucault, Michel. 1985. História da Sexualidade III. O Cuidado de Si. Rio de Janeiro, Graal. . 1990. "Omnes et Singulatium: Por uma crítica da 'razão política". In. Novos Estudos CEBRAP, no 26, pp. 77-99. 1999. História da sexualidade II. O uso dos prazeres. Rio de Janeiro: Graal. 2004. A Hermenêutica do Sujeito. São Paulo: Martins Fontes.

Geertz, Clifford. 2008. "Descrição densa: por uma teoria interpretativa da cultura". In: $A$ Interpretação das Culturas. Rio de Janeiro: LTC, pp. 2-24.

Gell, Alfred. 1998. Art and Agency: An Anthropological Theory. Oxford: Clarendon Press. Guattari, Félix; ROLNIK, Suely. 2005. Micropolitica: cartografias do desejo. Petrópolis: Vozes. Kleinman, Arthur. 2006. What Really Matters: Living a moral life amidst uncertainty and danger. NY: Oxford University Press.

Mignot, Elise. 2015. "Pragmatic and sylistic uses of personal pronoun one". In. Gardelle, Laurie \& Sorlin, Sandrine. The Pragmatics of Personal Pronouns. John Benjamins Publishing.

Simmel, Georg. 2005. "As grandes cidades e a vida do espírito". In. Mana. Rio de Janeiro, v. 11, n. 2, p. 577-591. 
Sontag, Susan. 2003. Diante da dor dos outros. São Paulo: Cia das Letras.

Velho, Gilberto. 2003. Projeto e Metamorfose: antropologia das sociedades complexas. Rio de Janeiro: Zahar.

Wagner, Roy. 2015. A invenção da Cultura. São Paulo: Cosac \& Naify.

\section{Where Art, ANTHRopology and Politics CAN MEET: Personalisation AND METAPHYSICS OF INTERIORITY IN DISCOURSES ON SUFFERING}

This essay explores the possibility of collectivizing individual experiences of suffering - built by the production of anthropological and visual artists works - based on personalization processes. By that term, I understand the discursive elaboration that produces an identification with the interlocutors whose effectiveness lies in sharing a generic recognition as humanity. For this, the productions of artists and anthropologists operate metaphysics of interiority; that is, using stylistic mechanisms capable of emotionally triggering the interlocutors of the text or work. It is understood that anthropology and art can produce political agencies in a similar way, sharing a number of like socio-political issues.

Keywords: anthropology of art, politics, suffering, collectivization

Recebido em: 2020-09-02

Aceite em: 2021-04-02 